Lucas Filipe Martins da Silva Andreas Öchsner

Editors

Modeling of

Adhesively Bonded

Joints

Springer 


\title{
Progressive Damage Modelling
}

moment.

\author{
Marcelo F.S.F de Moura
}

nuctures.

tp joints.

uminated

Part III:

instanten

\begin{abstract}
The application of bonded joints is increasing due to their several advantages to alternative bonding methods. As a result, more efficient predictive tools are necessary to increase the confidence of designers. In this context, cohesive and continuum damage models acquire special relevancy owing to their capacity to simulate damage onset and growth. Both of these methodologies combine strength of materials with fracture mechanics, thus overcoming the limitations of each method. A cohesive mixed-mode damage model based on interface finite elements and accounting for ductile behaviour of adhesives is presented. The cohesive parameters of the constitutive softening law are determined using an inverse method applied to fracture characterization tests under pure modes, I and II. In this context a new data reduction scheme based on crack equivalent concept is developed and applied to fracture characterization tests. Good agreement between the numerical and experimental results was obtained for strength versus overlap length in singlelap joints. A continuum mixed-mode damage model is also presented using a triangular softening law adequate only for brittle or moderately ductile adhesives. In these models the material properties degradation occurs inside of the solid elements, which is advantageous relatively to cohesive methods mainly when damage propagation onset and path are not known a priori.
\end{abstract}

\subsection{Introduction}

Adhesive joints present several advantages over other conventional bonding methods like mechanically fastened joints. Adhesive joints present less sources of stress concentrations, more uniform load distribution and better fatigue properties. They

Marcelo F.S.F de Moura

Departamento de Engenharia Mecânica e Gestão Industrial, Faculdade de Engenharia, Universidade do Porto, Rua Dr. Roberto Frias, 4200-465 Porto, Portugal,

e-mail: mfmoura@fe.up.pt 
also provide higher flexibility to join different materials, allowing the choice of the better material for each component of a structure. To benefit from these advantages it is crucial to design bonded joints properly. There are two basic approaches: strength of materials and fracture mechanics based methods. These methods are described in more detail below.

\subsubsection{Failure Prediction Classical Methods}

\subsubsection{Strength of Materials}

In the strength of materials approach the maximum stress or strain criteria are the most popular ones. They are based on the assumption that failure occurs when one of the stress or strain tensor components attains the respective strength value. Harris and Adams [19] used with success the maximum principal stress and the maximum principal strain criteria in order to predict the failure of single lap joints. Ikegami et al. [20] used the von Mises stress criterion to predict the failure of scarf joints using metal and composite adherends and Charalambides et al. [4] applied the same criterion to double lap joints. They did not obtain accurate results due to dependence of adhesive behaviour on the hydrostatic stress, which is not accounted for in the von Mises criterion. Several different versions of these criteria were used by other authors. Lee and Lee [28] used the maximum shear strain criterion on single lap tubular joints. Crocombe and Adams [6] proposed the effective plastic strain criterion for peel tests. In these tests the triaxial strain is expressed as an effective one, which is compared to the uniaxial failure strain of bulk specimens.

The referred criteria have a main difficulty when applied to the failure prediction of bonded joints. In fact, in bonded joints a problem of stress singularity at the end of overlapping regions arises due to sharp corners. A stress singularity can be defined as a point where, according to linear elastic analysis, an infinite value of stress appears. Evidence of this problem can be detected in finite element analysis, when stresses at the singularity point increase with the mesh refinement and convergence cannot be reached. In conclusion, it can be affirmed that the stress based methods present mesh dependency during numerical analysis due to stress singularities. To overcome this problem the stresses obtained numerically are used in a point stress or average stress criteria [38] in order to evaluate the occurrence of failure. In the point stress criterion the stresses are evaluated at a characteristic distance (Fig. 6.1) whereas in the average stress criterion they are averaged over a distance. The failure occurs when these stress values attain the respective material strength. They can be viewed as semi-empirical criteria as the characteristic distance value is determined from experimental data. Towse et al. [36] used the criterion of critical strain at a given distance to predict failure of double lap joints. In this case, failure is simulated when the strain in the neighbouring region of the singularity reaches the respective limiting value. Although the obtained results agreed with the experimental ones, it should be emphasized that the characteristic distance was experimentally determined, which limits its use in other types of joints. John et al. [22] argues that

failure o the singt result in which is tion of $b$ the aver. adhesive Iap joint In su: provide of the a Howera use the charast tooll - no involved

In the st Lonlike anamis furing it if the dit life. the size. $T h$ da stres

The

binere I ixution. Eropaga 
hoice of the Idvantages it hes: strength described in

iteria are the irs when one value. Harris he maximum ints. Ikegami f scarf joints lied the same ue to depenccounted for were used by ion on single tic strain cri:ffective one,

ilure predic;ularity at the larity can be nite value of rent analysis, tent and con: stress based stress singuare used in a rence of failistic distance er a distance. rrial strength. tance value is on of critical ase, failure is y reaches the e experimensperimentally 2] argues that
Fig. 6.1 Stress or strain at a characteristic distance from the singularity

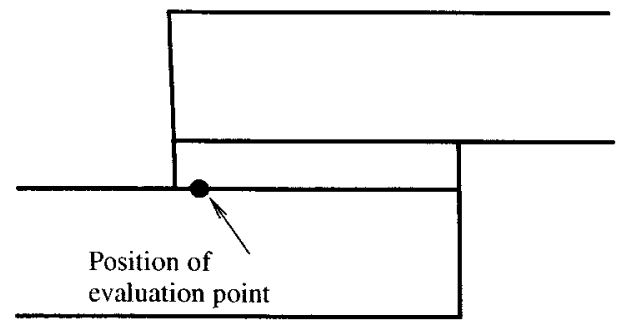

failure occurs when shear stress attains a critical value at a normalized distance from the singularity point in a double lap joint of unidirectional composite. However, this result implies that the critical distance varies as a function of the overlap length which is not physically sound. The average stress criterion applied to failure prediction of bonded joints was used by Zhao [42]. The critical dimension used to evaluate the average of the maximum principal stress was considered as being equal to the adhesive thickness. However, Charalambides et al. [4] demonstrated that for double lap joints the point of maximum stress occurs out of the characteristic region.

In summary it can be affirmed that the point and the average stress criteria can provide accurate results but they depend markedly on the previous determination of the characteristic distance, which is usually performed by experimental tests. However, the results can not be easily applied to different types of joints that do not use the same materials and geometry. In fact, the lack of a physical meaning of this characteristic distance renders impossible the establishment of general predictive tools, not depending on a parameter which is a function of type of loading, materials involved and joint geometry.

\subsubsection{Fracture Mechanics}

In the strength of materials approach, materials are assumed to be free of defects. Unlike to what happens in strength of materials based approaches, the fracture mechanics approach assumes the presence of an inherent defect in the material, induced during the fabrication process or during work. In this case the objective is to know if the defects can induce catastrophic failure or if, during the predicted structure life, they can propagate stably maintaining their dimensions inferior to the critical size. There are two types of fracture mechanics criteria. The criteria can be based on stress intensity factors or on the energetic concepts.

The stress intensity factor is defined as

$$
K=Y \sigma_{\mathrm{R}} \sqrt{\pi a}
$$

where $Y$ is a non-dimensional factor depending on the geometry and loading distribution, $\sigma_{\mathrm{R}}$ the remote applied stress and $a$ the crack length. It is assumed that crack propagation occurs when the stress intensity factor attains its critical value 


$$
K_{\mathrm{c}}=\sigma_{\mathrm{u}} \sqrt{\pi a}
$$

where $\sigma_{\mathrm{u}}$ is the strength of the material.

The energetic criterion is based on the assumption that crack growth will occur when the energy available at the crack tip ( $G$-strain energy release rate) and due to the applied loading, overcomes the critical strain energy release rate $\left(G_{\mathrm{c}}\right)$, which is a material property. The strain energy release rate is given by

$$
G=\frac{d W}{d A}-\frac{d U}{d A}
$$

where $W$ is the work realized by external forces, $U$ the internal strain energy and $d A$ the variation of crack surface.

It should be noted that $G$ and $K$ are intrinsically related. In fact, Irwin [21], demonstrated that in plane stress

$$
G=\frac{K^{2}}{E}
$$

and in plane strain

$$
G=\frac{K^{2}\left(1-v^{2}\right)}{E}
$$

where $E$ and $v$ are the Young's modulus and Poisson's ratio, respectively. These relationships are also valid for the respective critical values $\left(G_{\mathrm{c}}\right.$ and $\left.K_{\mathrm{c}}\right)$.

Crack growth can take place under three different modes, as it can be seen in Fig. 6.2. The mode I represents an open mode and the others (mode II and mode III) are the shear modes. In the majority of real situations the applied loading originates a combination of modes at the crack tip, which implies that a mixed-mode criterion should be considered in order to better simulate the damage propagation.

Several authors applied the fracture mechanics concepts to the failure strength prediction of bonded joints. The majority of the proposed works are based on the concepts of strain energy release rate. It is usually assumed that damage propagation occurs when the strain energy at the crack front is equal to the critical strain energy release rate, which is a material property. Kinloch [24] refers that energetic criterion is advantageous relatively to stress intensity factors approach. First the strain energy release rate has an important physical significance related to the energy absorption. Second, the value of stress intensity factors is not easily determinable, namely when the crack grows at or near to an interface. Ripling et al. [33] also

Fig. 6.2 Failure modes

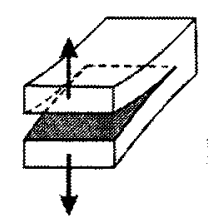

Mode I

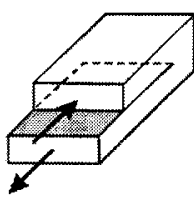

Mode II

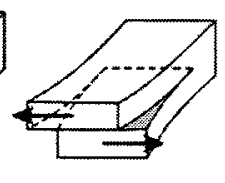

Mode III
Where criter:

Oitis

Virtusel metho tion th: necess resents The mi In a it: at this and : = movdes be at? asidte oratis: betwa where Arsola sar th: gurnt" 
th will occur (e) and due to $\left.G_{\mathrm{c}}\right)$, which is

nergy and $d A$

Ł. Irwin [21],

:tively. These

$$
\text { c). }
$$

an be seen in and mode III) ing originates sode criterion on.

ilure strength based on the e propagation strain energy lergetic criteirst the strain he energy abdeterminable, . al. [33] also

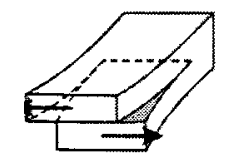

Mode III proposed the use of strain energy release rates instead of stress intensity factors recognizing the non-homogeneity of the bonded joints. However, it should be referred that the application of energetic criterion is not absent of some difficulties related to mixed-mode crack propagation. In fact, in homogeneous and isotropic materials cracks tend to propagate under mode I, perpendicularly to the direction of maximum principal stress, independently of the original crack. However, in a bonded joint, the crack growth direction is restricted by the adherends which leads, in most cases, to a mixed-mode crack propagation (I+II). Under these circumstances it is fundamental to use adequate energetic criteria which are generally in the form of

$$
\left(\frac{G_{\mathrm{I}}}{G_{\mathrm{Ic}}}\right)^{A}+\left(\frac{G_{\mathrm{II}}}{G_{\mathrm{II} \mathrm{c}}}\right)^{B}=1
$$

where $G_{\mathrm{Ic}}$ and $G_{\mathrm{IIc}}$ are the critical values in mode I and mode II. The linear energetic criterion $(A=B=1)$ and the quadratic one $(A=B=2)$ are the most used.

One of the most popular methods based on fracture mechanics soncepts is the Virtual Crack Closure Technique (VCCT), which is detailed by Krueger [25]. The method allows obtaining the strain energy release rates and is based on the assumption that, when a crack grows the energy released in this process is equal to the work necessary to close the crack to its initial length before propagation. Figure 6.3 represents a two-dimensional problem where the crack grows from the node $l$ to node $i$. The method can be applied by two different ways. The first one consists in two steps. In a first run, node $l$ is closed and the forces in the mode I and mode II directions at this node are registered. In a second run, node $l$ is opened originating nodes $l_{1}$ and $l_{2}$ and, by applying the same loading, the relative displacements between these nodes in the respective directions are also measured. However, the method can also be applied in a sole run. In this case, it is necessary to use a refined mesh and to assure that self-similar crack propagation exists. The energy necessary to close the crack is obtained by multiplying the loads at node $i$ by the relative displacements between nodes $l_{1}$ and $l_{2}$

$$
\Delta E=\frac{1}{2}\left(X_{i} \Delta u_{l}+Y_{i} \Delta v_{l}\right)
$$

where $X_{i}, Y_{i}$ represent the loads at the closed node $i$ and $\Delta u_{l}, \Delta v_{l}$ the difference of displacements between nodes $l_{1}$ and $l_{2}$. The respective strain energy release rates can then be calculated by the product of the relative displacements at the "opened point" (nodes $l_{1}$ and $l_{2}$ ) and the loads at the "closed point" (node $i$ )

$$
\begin{aligned}
G_{\mathrm{I}} & =\frac{1}{2 b \Delta a} Y_{i} \Delta v_{l} \\
G_{\mathrm{II}} & =\frac{1}{2 b \Delta a} X_{i} \Delta u_{l}
\end{aligned}
$$

being $b \Delta a$ the area of the new surface created by an increment of crack propagation (see Fig. 6.3).

Using the energetic criterion expressed by Eq. (6.6), propagation will occur when the values of $G_{\mathrm{I}}$ and $G_{\mathrm{II}}$ obtained from Eq. (6.8) satisfy the criterion. It should be 
Fig. 6.3 The virtual crack closure technique (VCCT)

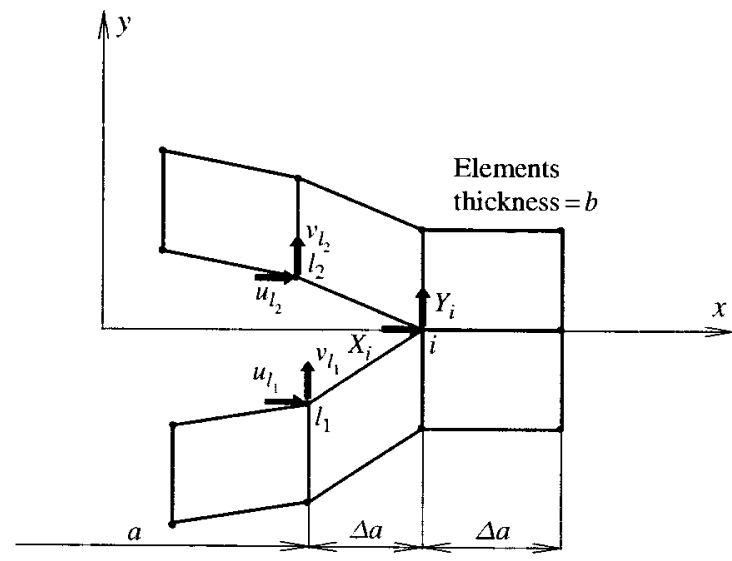

noted that the method can be easily applied in three-dimensional problems, where mode III can be obtained using the same procedure described for the other modes.

It should be referred that the use of fracture mechanics criteria depends on the existence of some kind of defect which is usually simulated as a pre-crack. These initial cracks are artificially introduced and intend to simulate damage or defects originated during the fabrication process or induced in service. Thus, it can be affirmed that fracture mechanics based criteria are more adequate for damage growth instead of its initiation. On the other hand, there are some difficulties associated to this approach. In fact, the initial crack length size and its locus constitute two main difficulties characteristic of the method.

\subsubsection{Actual Trends}

The stress and fracture mechanics based criteria present some disadvantages. The stress based methods present mesh dependency during numerical analysis due to stress singularities. On the other hand, the point/average stress criteria require the definition of a critical dimension which depends on loading, materials and joint geometry, and do not have a physical theoretical foundation. Fracture mechanics approach relies on the definition of an initial flaw or crack length. However, in many structural applications the damage initiation locus is not obvious. On the other hand, the stress-based methods behave well at predicting damage onset, and fracture mechanics has already demonstrated its accuracy in the crack propagation modelling. In order to overcome the referred drawbacks and exploit the usefulness of the described advantages, cohesive damage models and continuum damage mechanics emerge as suitable options. These methodologies combine aspects of stress based analysis to model damage initiation and fracture mechanics to deal with damage propagation. Thus, it is not necessary to take into consideration an initial defect and mesh dependency problems are overcome. Chapters 7 and 8 also deal with this methodology.

\section{$6.2 \mathrm{Col}$}

The use the most is related age. No interventi and relati tion of $\mathbf{m}$ conventic fracture spectivel finite ele Those el in several importan well defin hesive an cohesive

In the have beel age mode in tensior displacen haviour o lengths o including joints. A was to in results ri tests und pend on depender to study $t$ For the a was used aluminiu law for el specimen to failure. mined co then appl fracture process Z works w

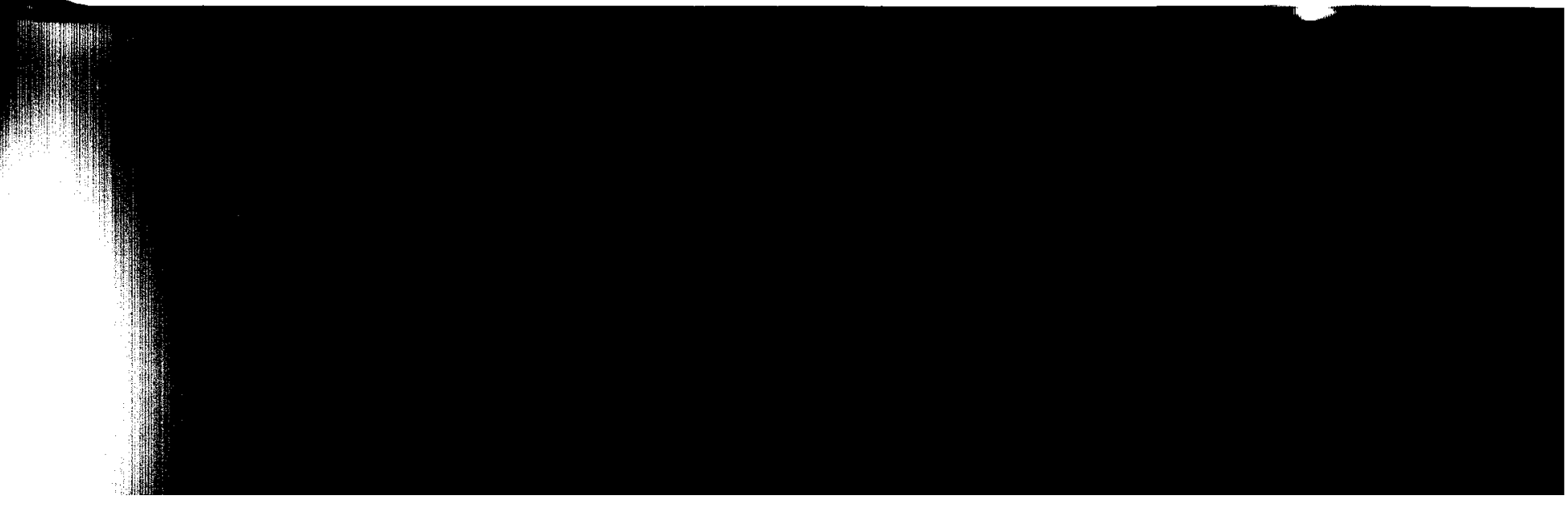




\subsection{Cohesive Damage Models}

ments

:kness $=b$

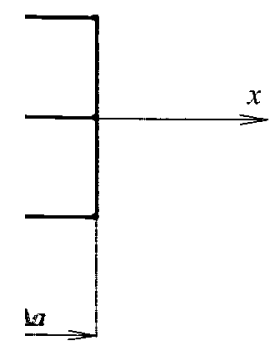

problems, where the other modes. teria depends on d as a pre-crack. aulate damage or vice. Thus, it can quate for damage : difficulties asso$s$ locus constitute

Isadvantages. The I] analysis due to riteria require the aterials and joint acture mechanics However, in many In the other hand, , and fracture megation modelling. fulness of the deamage mechanics ts of stress based leal with damage I an initial defect Uso deal with this
The use of cohesive damage models in fracture problems has become frequent in the most recent years. One of the most important advantages of cohesive models is related to their capacity to simulate onset and non-self-similar growth of damage. No initial crack is needed and damage propagation takes place without user intervention. They are usually based on a softening relationship between stresses and relative displacements between crack faces, thus simulating a gradual degradation of material properties. They do not depend on a predefined initial flaw unlike conventional fracture mechanics approaches. Typically, stress based and energetic fracture mechanics criteria are used to simulate damage initiation and growth, respectively. Usually, cohesive damage models are based on spring $[7,26]$ or interface finite elements $[9,30,31]$ connecting plane or three-dimensional solid elements. Those elements are placed at the planes where damage is prone to occur which, in several structural applications, can be difficult to identify a priori. However, an important characteristic of bonded joints is that damage propagation is restricted to well defined planes corresponding to the ones near or at the interfaces between adhesive and adherends or inside the adhesive, thus leading to a typical application of cohesive methods.

In the context of adhesive joints, some works considering the cohesive approach have been reported. Gonçalves et al. [18] considered a mixed-mode cohesive damage model to simulate the debonding process of aluminium single-lap joints loaded in tension. A triangular traction-separation law was used. The experimental loaddisplacement curves and failure loads were accurately predicted when the plastic behaviour of the materials was included in the analysis, for the entire range of overlap lengths considered. Blackman et al. [2] used a cohesive zone model (CZM) approach including two parameters, $G_{\mathrm{c}}$ and $\sigma_{\max }$, to study the fracture of adhesively bonded joints. A polynomial traction-separation law was considered. The main objective was to investigate the physical significance of $\sigma_{\max }$. Experimental and numerical results were compared using the Tapered Double Cantilever Beam (TDCB) and peel tests under mode I load. It was concluded that the specimen compliance and $G_{\mathrm{c}}$ depend on the value of $\sigma_{\max }$ until a relatively high value of this parameter, when the dependence significantly diminished. A CZM was also employed by Yang et al. [39] to study the coupling between interface fracture and plastic strain of the adherends. For the adhesive, a trapezoidal shape traction-separation law, including plasticity, was used. The model was validated performing T-peel tests on adhesively bonded aluminium joints. The same authors [41] considered a similar traction-separation law for elastic-plastic mode II crack growth modelling. End Notched Flexure (ENF) specimens subjected to a bending load, and undergoing extensive plastic strain prior to failure, were used to validate the model. The main fracture parameters were determined comparing numerical and experimental results for a particular geometry, and then applied to other geometries. Yang and Thouless [40] simulated the mixed-mode fracture of joints bonded with ductile adhesives using a mode-dependent embedded process zone (EPZ) model. Mode I and mode II fracture laws obtained from previous works were combined with a mixed-mode failure criterion to provide quantitative 
predictions of the deformation and fracture of T-peel specimens and single-lap shear joints. A linear toughness based criterion was used to access complete failure of the EPZ elements and subsequent damage growth. Thouless et al. [35] used a cohesivezone approach to model the mixed-mode fracture of adhesively bonded Glass Fibre Reinforced Plastic single-lap joints. Three and two parameter damage laws were used for mode-I and for mode-II, respectively. The three-parameter (interface cohesive strength, characteristic strength and toughness) mode-I traction-separation law was used in order to simulate interfacial cracking followed by fibre pull-out (experimentally observed for mode-I fracture). On the other hand, mode II tests indicated that only few fibres were pulled out during mode-II fracture. Consequently, a two parameter (interface cohesive strength and toughness) trapezoidal traction-separation law was used to simulate the behaviour of the adhesive layer in mode-II. Experimental and numerical curves revealed excellent agreement, including both the strengths of the joints and the failure mechanisms. Andersson and Stigh [1] used an inverse method to determine the cohesive parameters of a ductile adhesive layer loaded in peel using equilibrium of energetic forces acting on a Double Cantilever Beam (DCB) specimen. This method consists on fitting the load-displacement curves, up to a predefined agreement is achieved, thus defining the used cohesive parameters. They verified that the stress-relative displacement curve can be divided in three parts. Initially the stress increases proportionally to the elongation (linear elastic behaviour of the layer), until a limit stress is achieved. A plateau region is then observed, corresponding to the plastic behaviour of the adhesive. The curve ends with a parabolic softening part. Leffler et al. [29] performed an identical analysis to determine the complete stress versus deformation relation of a thin adhesive layer loaded in shear, using the ENF specimen. The used method included the determination of the energy release rate as a function of the shear deformation at the crack tip, followed by derivation of the traction-separation relation using an inverse method. An approximate trapezoidal relation was obtained.

\subsubsection{Cohesive Damage Model Including Plastic Behaviour}

A cohesive mixed-mode (I+II) damage model was developed in order to simulate damage initiation and growth in bonded joints. The model is implemented via interface finite elements including a constitutive softening law which relates stresses $(\sigma)$ and relative displacements $\left(\delta_{\mathrm{r}}\right)$ between homologous points. The constitutive law presents a trapezoidal shape to account for the ductile behaviour typical of many adhesives (see Fig. 6.4). It should be noted that the triangular law, which can be used for brittle or moderately ductile adhesives, is a particular case of this trapezoidal one. Before damage starts to grow

$$
\sigma=\mathbf{E} \delta_{\mathbf{r}}
$$

where $\mathbf{E}$ is a diagonal matrix containing the interface stiffnesses $\left(e_{i}, i=\mathrm{I}, \mathrm{II}\right)$. These are defined as the ratio between the Young's (mode I) or shear modulus (mode II),

where streigi

The II aedess are ge the $10 \mathbb{1}$ Fialiare when 
e-lap shear lure of the I cohesiveJlass Fibre laws were face coheration law aut (exper5 indicated i. a two paseparation 'xperimene strengths an inverse yer loaded ever Beam curves, up arameters. ad in three ear elastic on is then :urve ends analysis to esive layer determinazcrack tip, ie method.

o simulate 1 via intertresses $(\sigma)$ itutive law $\mathbf{L}$ of many ich can be this trape-

III). These (mode II),

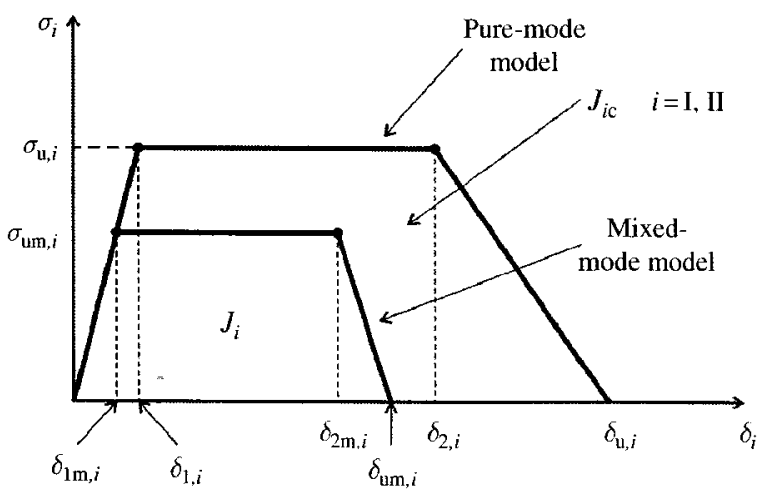

Fig. 6.4 The trapezoidal constitutive law for pure-mode and mixed-mode

and adhesive thickness. The effect of adhesive thickness is then included by this way and it could be neglected in the finite element mesh. In the pure-mode damage model, damage initiates when the relative displacement exceeds $\delta_{1, i}$. From this point up to final failure $\left(\delta_{\mathrm{u} . i}\right)$ a progressive softening is simulated in order to account for the different failure processes occurring in the vicinity of the crack tip. In this region, known as the Fracture Process Zone (FPZ), several damage processes, like plasticity and micro-cracking, take place, which is simulated by this softening law. Damage evolution is implemented through a damage parameter ranging between zero (undamaged) and one (complete failure). The softening relationship can be written as

$$
\sigma=(\mathbf{I}-\mathbf{D}) \mathbf{E} \delta_{\mathbf{r}}
$$

where $\mathbf{I}$ is the identity matrix and $\mathbf{D}$ is a diagonal matrix containing, in the position corresponding to mode $i(i=\mathrm{I}, \mathrm{II})$, the damage parameter, $d$. In the plateau region the damage parameter can be defined as

$$
d=1-\frac{\delta_{1, i}}{\delta_{i}}
$$

where $\delta_{1, i}(i=\mathrm{I}, \mathrm{II})$ is obtained from the initial stiffness $\left(e_{i}\right)$ and local cohesive strength in each mode $\sigma_{\mathrm{u}, i}(i=\mathrm{I}, \mathrm{II})$. In the stress softening part of the curve,

$$
d=1-\frac{\delta_{1, i}\left(\delta_{\mathrm{u}, i}-\delta_{i}\right)}{\delta_{i}\left(\delta_{\mathrm{u}, i}-\delta_{2, i}\right)}
$$

The rigorous definition of the second inflexion point $\left(\delta_{2, i}\right)$ in pure modes is not necessary since experience has shown that the precise details of the softening slope are generally not very significant. This issue will be discussed in more detail in the following sections. The maximum relative displacement, $\delta_{\mathrm{u}, i}$, at which complete failure occurs, is obtained by equating the area under the softening curve to $J_{i c}$, which corresponds to the respective critical fracture energy 


$$
J_{i \mathrm{c}}=\frac{\sigma_{\mathrm{u}, i}}{2}\left(\delta_{2, i}-\delta_{1, i}+\delta_{\mathrm{u}, i}\right)
$$

As in the majority of cases, bonded joints are subjected to mixed-mode (I+II) loading, a cohesive mixed-mode damage model, which is an extension of the pure-mode one, is also developed (Fig. 6.4). Damage initiation is predicted using a quadratic stress criterion

$$
\begin{array}{ll}
\left(\frac{\sigma_{\mathrm{I}}}{\sigma_{\mathrm{u}, \mathrm{I}}}\right)^{2}+\left(\frac{\sigma_{\mathrm{II}}}{\sigma_{\mathrm{u}, \mathrm{II}}}\right)^{2}=1 & \text { if } \quad \sigma_{\mathrm{I}}>0 \\
\sigma_{\mathrm{II}}=\sigma_{\mathrm{u}, \mathrm{II}} & \text { if } \quad \sigma_{\mathrm{I}} \leq 0
\end{array}
$$

where $\sigma_{i}$ and $\sigma_{\mathrm{u}, i}(i=\mathrm{I}, \mathrm{II})$ represent, respectively, the stresses and local cohesive strengths in each mode. It is assumed that normal compressive stresses do not induce damage. Considering Eq. (6.9), the first Eq. (6.14) can be rewritten as a function of the relative displacements

$$
\left(\frac{\delta_{1 \mathrm{~m} . \mathrm{I}}}{\delta_{1, \mathrm{I}}}\right)^{2}+\left(\frac{\delta_{1 \mathrm{~m}, \mathrm{II}}}{\delta_{1, \mathrm{II}}}\right)^{2}=1
$$

where $\delta_{1 \mathrm{~m}, i}(i=\mathrm{I}, \mathrm{II})$ are the relative displacements in each mode corresponding to damage initiation. Defining an equivalent mixed-mode displacement

$$
\delta_{\mathrm{m}}=\sqrt{\delta_{\mathrm{I}}^{2}+\delta_{\mathrm{II}}^{2}}
$$

and a mixed-mode ratio

$$
\beta=\frac{\delta_{\mathrm{II}}}{\delta_{\mathrm{I}}}
$$

the equivalent mixed-mode relative displacement at the onset of the softening process $\left(\delta_{1 \mathrm{~m}}\right)$ is obtained combining Eqs. (6.15), (6.16), (6.17)

$$
\delta_{1 \mathrm{~m}}=\delta_{1, \mathrm{I}} \delta_{1, \mathrm{II}} \sqrt{\frac{1+\beta^{2}}{\delta_{1, \mathrm{I}^{2}}+\beta^{2} \delta_{1, \mathrm{I}}^{2}}}
$$

Stress softening onset $\left(\delta_{2 \mathrm{~m}}\right)$ is predicted using a relationship between the current relative displacements in each mode and the critical relative displacements, similar to the one considered for the damage initiation point (Eq. 6.15),

$$
\left(\frac{\delta_{2 \mathrm{~m}, \mathrm{I}}}{\delta_{2, \mathrm{I}}}\right)^{2}+\left(\frac{\delta_{2 \mathrm{~m}, \mathrm{II}}}{\delta_{2, \mathrm{II}}}\right)^{2}=1
$$

Using a procedure similar to the one followed for $\delta_{1 \mathrm{~m}}$, the mixed-mode relative displacement at the onset of the stress softening process $\left(\delta_{2 \mathrm{~m}}\right)$ can be obtained 


$$
\delta_{2 \mathrm{~m}}=\delta_{2, \mathrm{I}} \delta_{2, \mathrm{II}} \sqrt{\frac{1+\beta^{2}}{\delta_{2, \mathrm{II}}^{2}+\beta^{2} \delta_{2, \mathrm{I}}^{2}}}
$$

II) loadre-mode uadratic

:ohesive it induce iction of

nding to

ine pro-

Crack growth is simulated by the linear fracture energetic criterion

$$
\frac{J_{\mathrm{I}}}{J_{\mathrm{Ic}}}+\frac{J_{\mathrm{II}}}{J_{\mathrm{IIc}}}=1
$$

When Eq. (6.21) is satisfied, damage growth occurs and stresses are completely released, with the exception of normal compressive ones. The energy released in each mode at complete failure can be obtained from the area of the smaller trapezoid of Fig. 6.4

$$
J_{i}=\frac{\sigma_{\mathrm{um}, i}}{2}\left(\delta_{2 \mathrm{~m}, i}-\delta_{1 \mathrm{~m}, i}+\delta_{\mathrm{um}, i}\right)
$$

Combining Eqs. (6.16), (6.17), (6.22) and (6.21) it can be written

$$
\delta_{\mathrm{um}}=\frac{2 J_{\mathrm{Ic}} J_{\mathrm{IIc}}\left(1+\beta^{2}\right)-\left(\delta_{2 \mathrm{~m}}-\delta_{1 \mathrm{~m}}\right) \delta_{1 \mathrm{~m}}\left(e_{\mathrm{I}} J_{\mathrm{IIc}}+\beta^{2} e_{\mathrm{II}} J_{\mathrm{Ic}}\right)}{\delta_{1 \mathrm{~m}}\left(e_{\mathrm{I}} J_{\mathrm{IIc}}+\beta^{2} e_{\mathrm{II}} J_{\mathrm{Ic}}\right)}
$$

which corresponds to the ultimate relative displacement in mixed-mode.

The damage parameter can now be evaluated using the critical mixed-mode displacements (Eqs. (6.18), (6.20) and (6.23)) in Eqs. (6.11) and (6.12).

\subsection{Evaluation of Cohesive Parameters}

The accurate evaluation of cohesive parameters of the trapezoidal law is a fundamental task in order to obtain good strength predictions. The properties measured from tests in bulk specimens are not representative because in bonded joints the adhesive is a thin layer and behave differently than in bulk. The solution is to obtain the cohesive properties using specimens where the thickness of the adhesive is similar to the one used in bonded joints. This can be achieved with the Double Cantilever Beam (DCB) and End Notched Flexure (ENF) fracture characterization tests for pure mode I and mode II loading, respectively. The use of these tests to measure the cohesive parameters is described below.

\subsubsection{Fracture Energies}

In the following, the application of the DCB and ENF tests to fracture characterization of adhesives is described. A new data reduction scheme avoiding the inevitable inaccuracies present in the measurement of the crack length during propagation is highlighted. 


\subsubsection{The DCB Test}

The DCB is a standardized test (ASTM D3433-99) to measure material fracture properties under pure mode I loading. When applied to bonded joints it consists in two beams bonded with the required adhesive thickness with a predefined initial crack length. The load is applied in order to promote pure mode I loading at the crack front (Fig. 6.5).

There are two classical data reduction schemes frequently used to obtain the fracture energy in mode I $\left(J_{\mathrm{Ic}}\right)$. The Compliance Calibration Method $(\mathrm{CCM})$ is based on the Irwin-Kies equation [23]

$$
J_{\mathrm{Ic}}=\frac{P^{2}}{2 b} \frac{d C}{d a}
$$

being $C$ the compliance $(\delta / P)$. Using this method, the values of load, applied displacement and crack length $(P, \delta$ and $a)$ are registered in order to calculate the fracture energy during load history. Alternatively, the Corrected Beam Theory (CBT) is also commonly used [10]. In this case, it is assumed that $J_{\text {IC }}$ can be obtained from

$$
J_{\text {Ic }}=\frac{3 P \delta}{2 b(a+|\Delta|)}
$$

where $\Delta$ is a correction for crack tip rotation and deflection. $\Delta$ is determined from a linear regression analysis of $(C)^{1 / 3}$ versus $a$ data.

It should be emphasized that both methods depend on crack length measurements during its propagation. This is not easy to perform and remarkable errors can occur, affecting the measured $J_{\mathrm{Ic}}$. In order to overcome the referred difficulties, a new data reduction scheme based on crack equivalent concept is proposed. The method does not require crack length measurements and accounts for the energy dissipated at the Fracture Process Zone (FPZ). The FPZ develops ahead of the crack tip in consequence of the nucleation of multiple micro-cracks through the adhesive thickness and plastification. In fact, a quite extensive FPZ exists when ductile adhesives are used. This non negligible FPZ affects the measured toughness as a non negligible amount of energy is dissipated on it. Consequently, its influence should be taken into account, which does not occur when the real crack length is used in a classical data reduction scheme (Fig. 6.6).

The proposed method is based on beam theory and depends decisively on the beam compliance. Consequently, it is named Compliance Based Beam Method
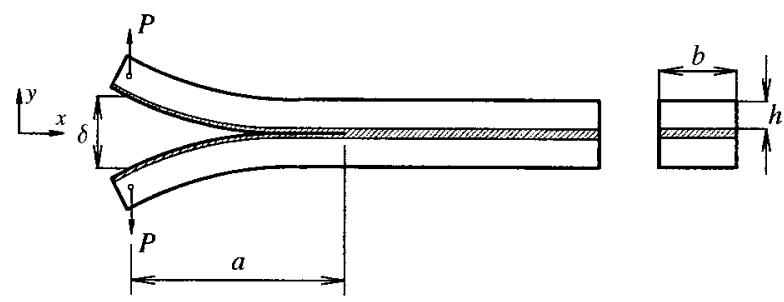

Fig. 6.5 Schematic representation of the DCB test 
srial fracture it consists in efined initial rading at the

ithe fracture based on the applied dislate the fracory (CBT) is ained from

nined from a leasurements irs can occur, s. a new data method does sipated at the tip in conseive thickness tdhesives are on negligible uld be taken in a classical sively on the eam Method
Fig. 6.6 Schematic representation of the FPZ and crack equivalent $\left(a_{e}\right)$ concept

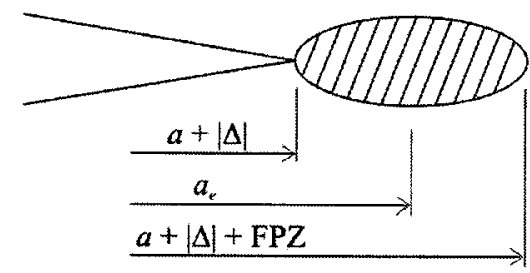

(CBBM). Following strength of materials analysis, the strain energy of the specimen due to bending and including shear effects is [14]

$$
U=2\left[\int_{0}^{a} \frac{M_{\mathrm{f}}^{2}}{2 E_{1} I} d x+\int_{0}^{a} \int_{-h / 2}^{h / 2} \frac{\tau^{2}}{2 G_{13}} b d y d x\right]
$$

where $M_{\mathrm{f}}$ is the bending moment, $I$ the second moment of area of the specimen, $b$ the specimen width, $E_{1}$ and $G_{13}$ the longitudinal and shear elastic properties of a general orthotropic material and

$$
\tau=\frac{3}{2} \frac{P}{b h}\left(1-\frac{4 y^{2}}{h^{2}}\right)
$$

being $y$ the coordinate along specimen thickness (Fig. 6.5). From Castigliano theorem the displacement $\delta$, can be written as

$$
\delta=\frac{\partial U}{\partial P}=\frac{8 P a^{3}}{E_{1} b h^{3}}+\frac{12 P a}{5 b h G_{13}}
$$

This equation constitutes an approach based on beam theory and does not account for all effects influencing the specimen behaviour. For example, it is known that stress concentrations arise around the crack tip, which is not taken into consideration by this approach. To overcome the referred discrepancies, an equivalent flexural modulus can be obtained from Eq. (6.28) and considering two initial conditions taken from the experimental tests: the initial crack length $a_{0}$ and initial compliance $C_{0}$. Moreover, this approach takes into account the variation of the material properties between different specimens at it is based on the experimentally measured $C_{0}$. Thus, $E_{\mathrm{f}}$ can be obtained from Eq. (6.28)

$$
E_{\mathrm{f}}=\left(C_{0}-\frac{12\left(a_{0}+|\Delta|\right)}{5 b h G_{13}}\right)^{-1} \frac{8\left(a_{0}+|\Delta|\right)^{3}}{b h^{3}}
$$

where $\Delta$ is the root rotation correction for the initial crack length (Fig. 6.6). In the beam theory it is assumed that each arm of the DCB specimen is an encastred beam whose length is equal to the crack length $a$. This parameter $(\Delta)$ can be achieved by a linear regression of $C^{1 / 3}=\mathrm{f}\left(a_{0}\right)$. The determination of $\Delta$ can be performed by slightly loading the specimen with three different initial crack lengths (Fig. 6.7) in order to define the $C^{1 / 3}=\mathrm{f}\left(a_{0}\right)$ linear regression (Fig. 6.8). 
Fig. 6.7 Schematic representation of the compliance calibration as a function of the crack length in the DCB test

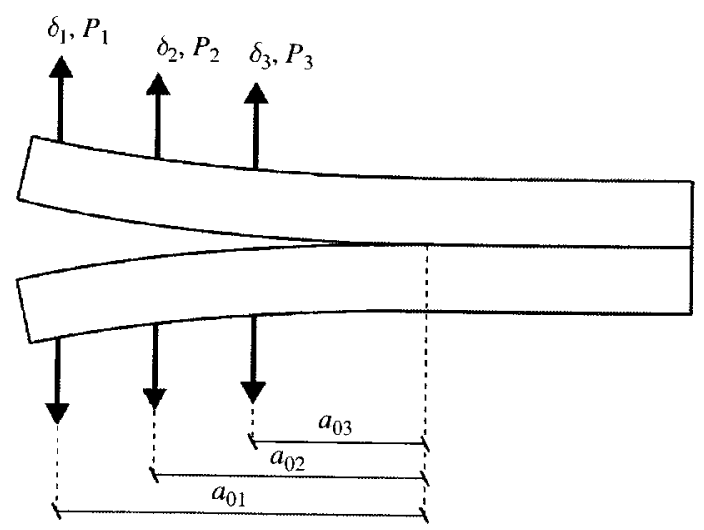

Alternatively, Wang and Williams [37] proposed another form of determining the root rotation effects by altering the crack length using the parameter $\Delta_{\mathrm{I}}$

$$
\Delta_{\mathrm{I}}=h \sqrt{\frac{E_{\mathrm{f}}}{11 G_{13}}\left[3-2\left(\frac{\Gamma}{1+\Gamma}\right)^{2}\right]} \text { and } \Gamma=1.18 \frac{\sqrt{E_{\mathrm{f}} E_{3}}}{G_{13}}
$$

which can be used instead of $\Delta$ in Eq. (6.29).

Owing to the difficulties inherent to crack monitoring during propagation and to energy dissipation in the FPZ, an equivalent crack length $a_{\mathrm{e}}$ (Fig. 6.6) is defined and used instead of the measured crack length. The equivalent crack length is obtained from Eq. (6.28) as a function of the specimen compliance registered during the test and considering $a_{\mathrm{e}}=a+|\Delta|+\Delta a_{\mathrm{FPZ}}$ instead of $a$. The solution of this equation can be found using the mathematical software Matlab ${ }^{(\mathrm{B})}$ and is presented in Appendix. The fracture energy in mode I can be obtained using Eq. (6.24)

$$
J_{\mathrm{Ic}}=\frac{6 P^{2}}{b^{2} h}\left(\frac{2 a_{\mathrm{e}}^{2}}{h^{2} E_{\mathrm{f}}}+\frac{1}{5 G_{13}}\right)
$$

The presented methodology allows obtaining the fracture energy $J_{\mathrm{Ic}}$ only as function of the $P-\delta$ data. For this reason it is designated by Compliance Based Beam Method

Fig. 6.8 Schematic representation of the crack length correction due to root rotation in the DCB test

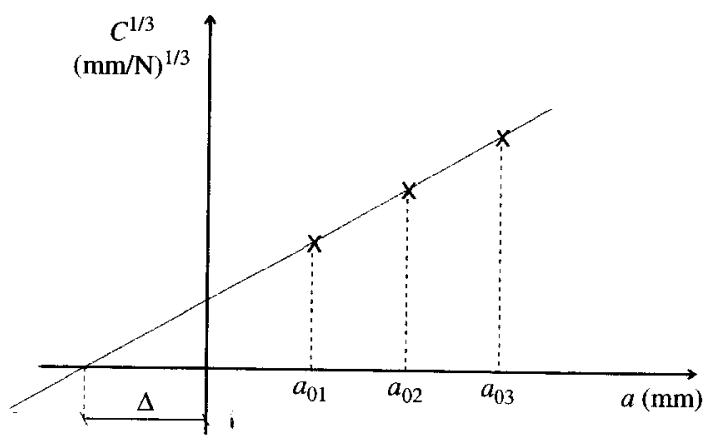


(CBBM). Using this method it is not necessary to measure the crack length during propagation because the calculated equivalent crack length is used instead of the real one. Another advantage is related to the fact that $a_{\mathrm{e}}$ includes the effect of the FPZ, which is not taken into account when the real crack length is considered. Moreover, the specimen modulus $\left(E_{\mathrm{f}}\right)$ is not a measured property but rather a computed one (Eq. (6.29)) as a function of the initial compliance, thus accounting for the material variability between different specimens. The only material property required in this approach is the shear modulus $G_{13}$. However, from Eq. (6.31) it is straightforwardly concluded that the term containing $G_{13}$ is negligible relatively to the one of $E_{\mathrm{f}}$. This means that a typical value of $G_{13}$ can be used and that it is not necessary to measure it for each specimen.

\subsubsection{The ENF Test}

Up to now there is no standardized test to measure the fracture energy of bonded joints under pure mode II loading. The most used are based on interlaminar fracture characterization tests of composite materials. In this context the End Notched Flexure (ENF), End Loaded Split (ELS) and Four-Point End Notched Flexure (4ENF) tests should be emphasized (Fig. 6.9).

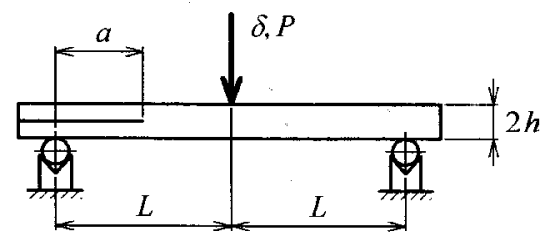

Fig. 6.9 Schematic representation of the ENF, ELS and 4ENF tests

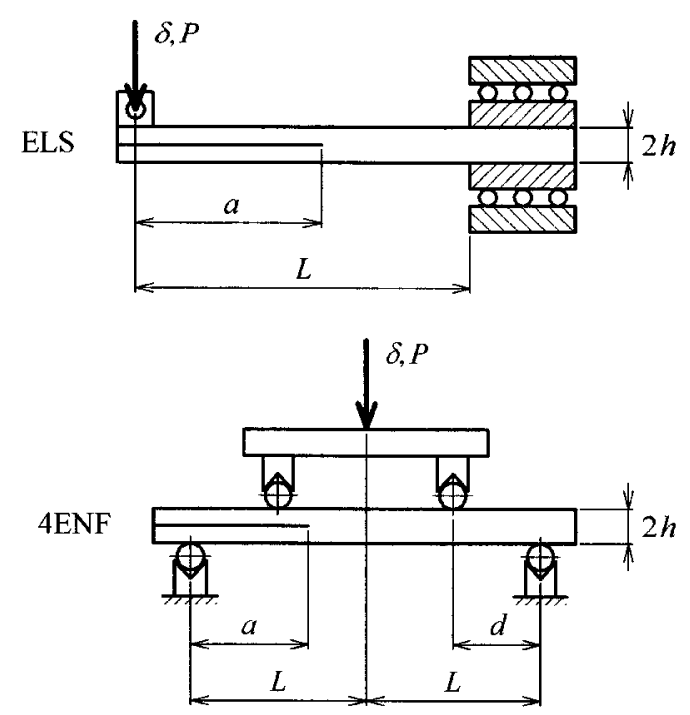


The ELS test presents some difficulties in the measurement of fracture energy related to large displacements effects and to sensibility of the clamping pressure conditions [14]. On the other hand, the 4ENF test requires a quite complex setup and some friction effects on the measured energy were detected [34]. The ENF test is the most simple to execute and consequently is frequently used for materials fracture characterization under pure mode II.

There are two main data reduction methods applied to ENF test in order to measure $J_{\text {IIc }}$ of bonded joints (Fig. 6.10). The CCM is also based on Eq. (6.24). The compliance calibration can be made by two different ways. One of them consists in performing bending tests using specimens with different initial cracks. This can be achieved using only one specimen by altering its position in the supports. Alternatively, the calibration of $C$ can be reached by measuring the crack length during propagation. A cubic polynomial fitting should be carried out considering

$$
C=C_{o}+m a^{3}
$$

which, using Eq. (6.24), leads to

$$
J_{\text {IIc }}=\frac{3 m a^{2} P^{2}}{2 b}
$$

Employ can be obts

The equis: initial crail

The Corrected Beam Theory proposed by Wang and Williams [37], can also be applied. The equation is

$$
J_{\mathrm{IIC}}=\frac{9 P^{2}\left(a+\left|\Delta_{\mathrm{II}}\right|\right)^{2}}{16 b^{2} E_{1} h^{3}}
$$

where $\Delta_{\mathrm{II}}$ is a crack length correction to account for shear. The authors showed that $\Delta_{\mathrm{II}}=0.42 \Delta_{\mathrm{I}}, \Delta_{\mathrm{I}}$ being the correction for mode I obtained for the DCB test (see Eq. (6.30)).

It should be emphasized that experimental difficulties in measuring the crack length are higher in mode II fracture characterization tests. In fact, due to applied loading the crack tends to close during propagation which hinders the clear visualization of its tip. On the other hand, the quite large effect of the FPZ size [8] is not accounted for when the real crack length is considered [11]. To overcome these difficulties an equivalent crack procedure, similar to the one used for DCB tests, can be followed to obtain the fracture energy under pure mode II loading using the ENF specimen. As in the DCB test, the method is based on beam compliance and beam theory and, consequently it is also named as CBBM.

Fig. 6.10 Schematic representation of the ENF test

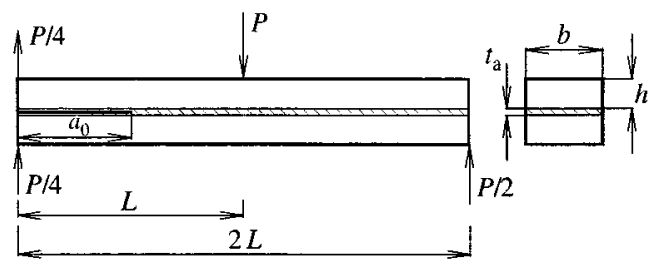

where $C_{2}$

This proce different $s$ e.g.. stress crack regio and their $E_{\mathrm{I}}$. Using for the FP: varies duri

di: $\sin \mathrm{n}$

where $\pi_{2} a$

In sumir Inoude I an: minasurem: Dalues of Complian thitt are pro nemi. Mor rask lengu crique mial neasured ail value : 
racture energy nping pressure complex setup 34]. The ENF d for materials

1 order to meaEq. (6.24). The them consists racks. This can upports. Alterlength during tering

7]. can also be Irs showed that DCB test (see

Iring the crack due to applied the clear visuFPZ size [8] is svercome these DCB tests, can using the ENF ance and beam

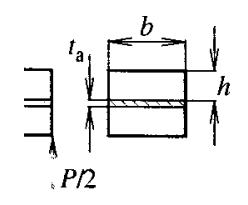

Employing the beam theory and Castigliano theorem, the equation of compliance can be obtained

$$
C=\frac{3 a^{3}+2 L^{3}}{8 E_{1} b h^{3}}+\frac{3 L}{10 G_{13} b h}
$$

The equivalent flexural modulus is obtained using the initial compliance $C_{0}$ and initial crack length $a_{0}$

$$
E_{\mathrm{f}}=\frac{3 a_{0}^{3}+2 L^{3}}{8 b h^{3}}\left(C_{0}-\frac{3 L}{10 G_{13} b h}\right)^{-1}
$$

This procedure takes into account the variation of the material properties between different specimens and for several effects that are not included in the beam theory, e.g., stress concentration at the crack tip and contact between the two arms at the precrack region. In fact, these effects influence the $P-\delta$ curve even in the elastic regime, and their effects are included when the initial compliance is used to determine the $E_{\mathrm{f}}$. Using $E_{\mathrm{f}}$ (Eq. (6.36)) instead of $E_{1}$ in Eq. (6.35), an equivalent crack accounting for the FPZ effects is achieved as a function of the beam compliance $(C)$ which varies during propagation

$$
a_{\mathrm{e}}=a+\Delta a_{\mathrm{FPZ}}=\left[\frac{C_{\mathrm{c}}}{C_{0 \mathrm{c}}} a_{0}^{3}+\frac{2}{3}\left(\frac{C_{\mathrm{c}}}{C_{0 \mathrm{c}}}-1\right) L^{3}\right]^{1 / 3}
$$

where $C_{\mathrm{c}}$ and $C_{0 \mathrm{c}}$ are given by

$$
C_{\mathrm{c}}=C-\frac{3 L}{10 G_{13} b h} ; \quad C_{0 \mathrm{c}}=C_{0}-\frac{3 L}{10 G_{13} b h}
$$

$J_{\text {IIc }}$ can now be obtained using the Irwin-Kies relation (Eq. (6.24))

$$
J_{\text {IIc }}=\frac{9 P^{2} a_{\mathrm{e}}^{2}}{16 b^{2} E_{\mathrm{f}} h^{3}}
$$

where $a_{\mathrm{e}}$ and $E_{\mathrm{f}}$ are given by Eqs. (6.37) and (6.36), respectively.

In summary, this data reduction scheme applied to fracture characterization in mode I and in mode II presents several advantages. Using this methodology, crack measurements are unnecessary. Experimentally, it is only necessary to register the values of applied load and displacement. Therefore, the method is designated as Compliance Based Beam Method (CBBM). Using this procedure the FPZ effects, that are pronounced in mode II tests, are included in the fracture energy measurement. Moreover, the flexural modulus is calculated from the initial compliance and crack length, thus avoiding the influence of specimen variability on the results. The unique material property needed in this approach is $G_{13}$. However, its effect on the measured fracture energy was found to be negligible [14], which means that a typical value can be used rendering unnecessary to measure it. 


\subsubsection{Cohesive Critical Displacements}

In order to define completely the cohesive damage model it is also necessary to determine the critical displacements corresponding to the inflexion points $\left(\delta_{1 . i}, \delta_{2 . i}\right)$. The first one is intrinsically associated to adhesive local strength $\left(\sigma_{\mathrm{u}, i}\right)$ and the second one defines the extent of the plateau region (Fig. 6.4). As already referred, these properties do not correspond to that of the adhesive as a bulk material.

The definition of the cohesive parameters is performed using an inverse method applied to fracture tests in mode I (DCB) and mode II (ENF). The method consists in three main steps. Initially, the experimental $R$-curve is obtained from the $P-\delta$ curve, applying the CBBM (Fig. 6.11). The plateau region of the $R$-curve corresponds to the fracture energy of the adhesive.

The second step consists in a numerical simulation of the test, using the cohesive damage model to simulate damage initiation and growth. In this simulation the measured fracture energy is an inputted parameter in the numerical approach. The other two cohesive parameters $\left(\delta_{1, i}, \delta_{2, i}\right)$ can be found by a trial and error procedure. An iterative process should be performed until a good accuracy between the numerical and experimental $P-\delta$ curves is obtained, thus defining the cohesive parameters $\left(\delta_{1, i}, \delta_{2, i}\right)$. This procedure depends on the number of parameters to be fixed. In fact, if the two referred parameters should be accurately determined, a genetic algorithm including an optimisation strategy should be used [16]. However, in some cases only one parameter $\left(\delta_{1, i}\right)$ is necessary. This happens when brittle adhesives are used. In
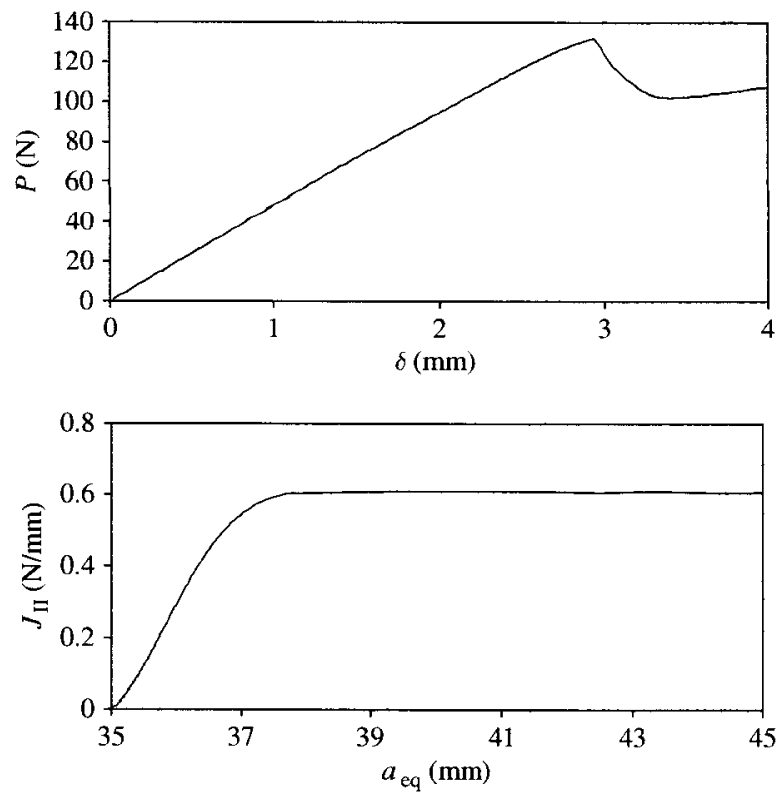

The $\mathrm{n}$ epox: The at prepre all $\mathbb{P T}$ ing or Hunts $\operatorname{ing} 5$ deant th ass

6.33.

The

$m=$ ?

is 2

iampe IIT-

Fig. 6.11 A typical $P-\delta$ curve of the ENF test (above) and the respective $R$-curve obtained using the CBBM (below) 
these cases, the trapezoidal law converts into a triangular one. Another case occurs when the model is not sensible to the value of $\delta_{2, i}$. In this situation, this parameter can be arbitrarily defined imposing, for the third part of the softening law, a symmetrical slope relatively to the initial linear part. de Moura et al. [15], performed a parametrical study on single lap joints and verified that even for ductile adhesives, there is a quite large range of values of $\delta_{2, i}$ that do not alter the predicted joint strength. The authors concluded that $\delta_{2, i}$ can be defined as the point that leads to the third part of the curve being symmetrical relatively to the initial linear part. This choice implies that $\delta_{2, i}$ falls in the values range leading to joint maximum strength. When only one cohesive parameter has to be determined, the iterative process can be easily performed. In fact, two or three attempts are usually enough to obtain an acceptable agreement between the numerical and experimental $P-\delta$ curves, thus leading to the definition of $\delta_{1, i}$.

\subsubsection{Fracture Characterization of Bonded Joints}

The method described above was applied to fracture characterization of carbonepoxy bonded joints under pure mode I (DCB test) and pure mode II (ENF test). The adherends were unidirectional $0^{\circ}$ lay-ups with sixteen layers of carbon/epoxy prepreg (TEXIPREG HS $160 \mathrm{RM}$ ) with $0.15 \mathrm{~mm}$ of ply thickness, whose mechanical properties are presented in Table 6.1 [3]. Curing was achieved in a press during one hour at $130^{\circ} \mathrm{C}$ and 4 bar pressure. The adhesive Araldite ${ }^{\circledR} 2015$ from Huntsmann (Basel, Switzerland) was used ( $E=1850 \mathrm{MPa}, v=0.3$ ) [3]. The bonding process included roughening the surfaces to be bonded with sandpaper and cleaning with acetone to increase the adhesion and avoid adhesive failure, followed by assembly and holding with contact pressure and curing at room temperature.

\subsubsection{DCB Tests}

The nominal dimensions of the DCB specimen were $2 h=5 \mathrm{~mm}, L=120 \mathrm{~mm}$, $b=15 \mathrm{~mm}, a_{0}=45 \mathrm{~mm}$ and adhesive thickness equal to $0.2 \mathrm{~mm}$. The specimens were tested under a tensile loading using an INSTRON testing machine at room temperature under displacement control. The loading rate was kept constant at $2 \mathrm{~mm} / \mathrm{min}$.

During the test the $P-\delta$ curves were registered in order to obtain the respective $R$-curves using the proposed CBBM. The plateau region of the $R$-curve defines the

Table 6.1 Carbon-epoxy elastic properties [3]

\begin{tabular}{lll}
\hline$E_{1}=1.09 \mathrm{E}+05 \mathrm{MPa}$ & $v_{12}=0.342$ & $G_{12}=4315 \mathrm{MPa}$ \\
$E_{2}=8819 \mathrm{MPa}$ & $v_{13}=0.342$ & $G_{13}=4315 \mathrm{MPa}$ \\
$E_{3}=8819 \mathrm{MPa}$ & $v_{23}=0.380$ & $G_{23}=3200 \mathrm{MPa}$ \\
\hline
\end{tabular}




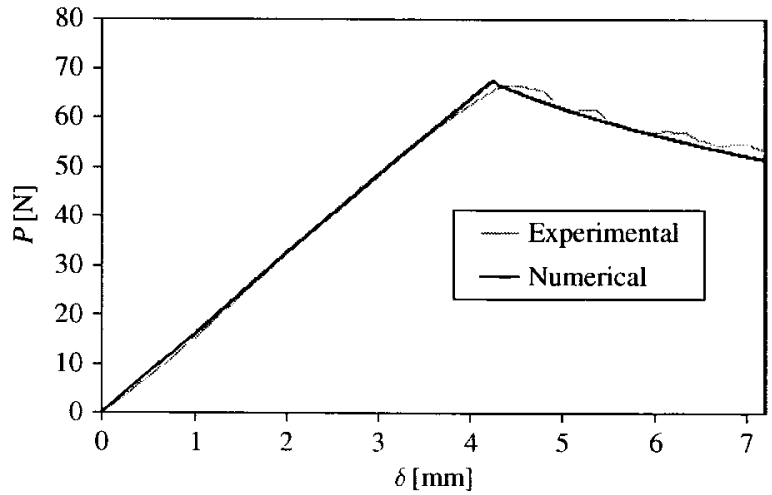

Fig. 6.12 Comparison between numerical and experimental $P-\delta$ curves

$J_{\text {Ic }}$ value which is an inputted parameter of the cohesive damage model. An iterative procedure is followed until a good agreement between numerical and experimental $P-\delta$ curves are achieved (Fig. 6.12), thus determining the remaining cohesive properties of the trapezoidal softening law. After some attempts, it was verified that local strength $\sigma_{\mathrm{u}, \mathrm{I}}$ (or $\delta_{\mathrm{l}, \mathrm{I}}$ ) does not have too much influence and only $\delta_{2, \mathrm{I}}$ was varied to fit the $P-\delta$ curves. $\sigma_{\mathrm{u}, \mathrm{I}}$ was set equal to $23 \mathrm{MPa}$.

Afterwards, the numerical and experimental $R$-curves are also compared (Fig. 6.13) in order to check the validity of the proposed model. Generally, good agreement was observed for all tests (Table 6.2) for the inputted and numerically obtained $J_{\text {Ic }}$ - plateau values corresponding to stable crack propagation. The values of the remaining cohesive parameter are also listed in Table 6.2.

\subsubsection{ENF Tests}

The nominal dimensions of the ENF specimen are $2 h=5 \mathrm{~mm}, L=100 \mathrm{~mm}$, $b=15 \mathrm{~mm}, a_{0}=70 \mathrm{~mm}$ and adhesive thickness equal to $0.2 \mathrm{~mm}$. The numerical-

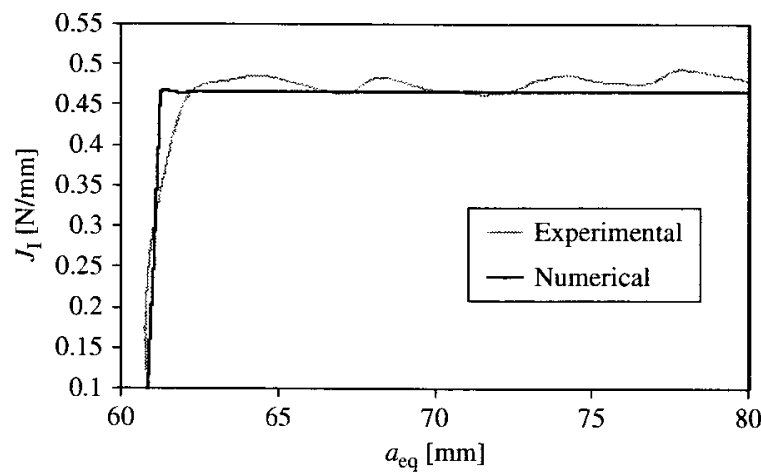

Fig. 6.13 Comparison between numerical and experimental $R$-curves 
Table 6.2 Comparison between numerical and experimental $J_{\text {IC }}$ and the obtained $\delta_{2, \mathrm{I}}$

\begin{tabular}{llll}
\hline & $\begin{array}{l}\text { Experimental } J_{\mathrm{Ic}} \\
(\mathrm{N} / \mathrm{mm})\end{array}$ & $\begin{array}{l}\text { Numerical } J_{\mathrm{lc}} \\
(\mathrm{N} / \mathrm{mm})\end{array}$ & $\begin{array}{l}\delta_{2 . \mathrm{I}} \\
(\mathrm{mm})\end{array}$ \\
\hline 1 & 0.484 & 0.482 & 0.021 \\
2 & 0.444 & 0.441 & 0.019 \\
3 & 0.420 & 0.415 & 0.018 \\
4 & 0.333 & 0.331 & 0.014 \\
5 & 0.406 & 0.404 & 0.018 \\
6 & 0.468 & 0.466 & 0.020 \\
Average & $\mathbf{0 . 4 2 5}$ & 0.422 & 0.018 \\
St. Dev. & 0.054 & 0.055 & 0.003 \\
\hline
\end{tabular}

An iterative sxperimental hesive propied that local tas varied to

o compared ierally, good numerically เ. The values

$=100 \mathrm{~mm}$,

e numerical-

experimental fitting procedures of $P-\delta$ curves were more complex in the ENF than in the DCB test. In fact, some sensibility to the two inflexion points $\left(\delta_{1, \mathrm{II}}, \delta_{2, \mathrm{II}}\right)$ was observed, which required a larger number of iterations in order to obtain a good agreement between the $P-\delta$ curves (Fig. 6.14).

The CBBM also provides good agreement between the inputted and measured $J_{\text {IIc }}$ (plateau values of the $R$-curves in Fig. 6.15), which demonstrates the adequacy of the method in order to measure the fracture energy in pure mode II of bonded joints. The values of the cohesive parameters obtained by the inverse method are listed in Table 6.3 for five experimental tests.

In summary, it can be affirmed that the numerical model shows that the values of fracture energies obtained by applying the CBBM are in excellent agreement with the ones inputted in the cohesive damage model. This proves that the referred data reduction scheme is able to reproduce the real values of fracture energy of the specimens. Is should be noted that generally the predicted values are a little bit inferior to the inputted ones. This can be explained by the presence of spurious modes at the specimens' edges. For example, de Moura et al. [13] demonstrated that $1.14 \%$ of the total energy available at the specimen edges comes from mode III loading.

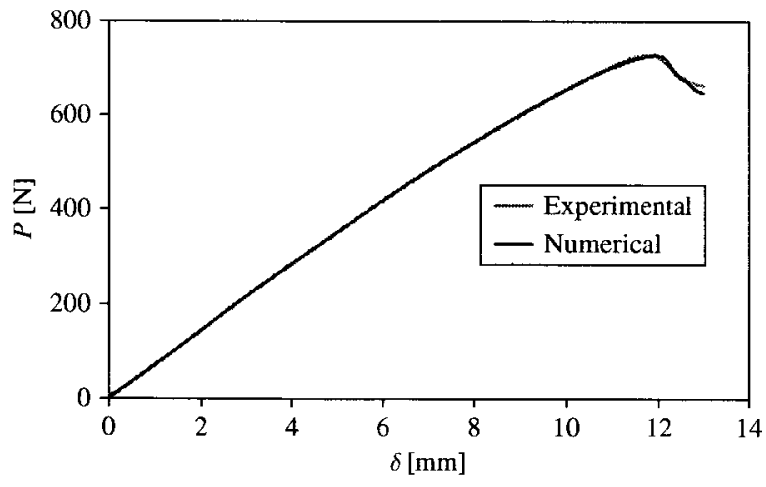

Fig. 6.14 Comparison between numerical and experimental $P$ - $\delta$ curves 


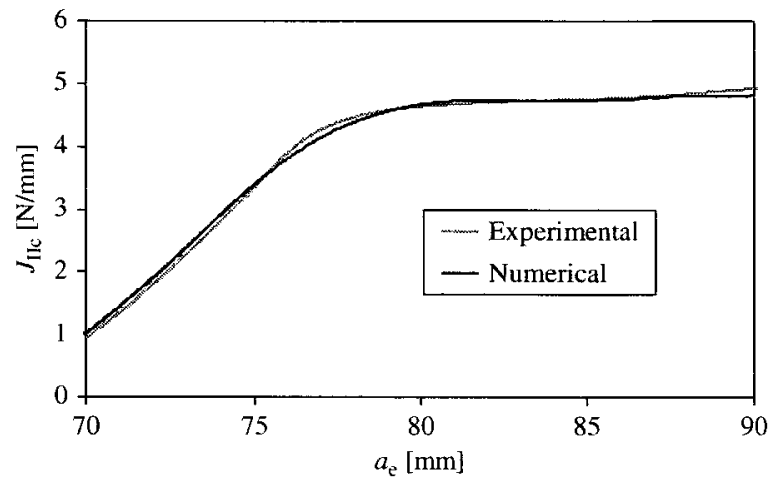

Fig. 6.15 Comparison between numerical and experimental $R$-curves

Table 6.3 Comparison between numerical and experimental $J_{\text {IIc }}$ and the calculated cohesive parameters $\left(\sigma_{\mathrm{u}, \mathrm{II}}\right.$ and $\left.\delta_{2, \mathrm{II}}\right)$

\begin{tabular}{lllll}
\hline & $\begin{array}{l}\text { Experimental } J_{\mathrm{IIc}} \\
(\mathrm{N} / \mathrm{mm})\end{array}$ & $\begin{array}{l}\text { Numerical } J_{\mathrm{II}} \\
(\mathrm{N} / \mathrm{mm})\end{array}$ & $\begin{array}{l}\sigma_{\mathrm{u}, \mathrm{II}} \\
(\mathrm{MPa})\end{array}$ & $\begin{array}{l}\delta_{2, \mathrm{II}} \\
(\mathrm{mm})\end{array}$ \\
\hline $\mathbf{1}$ & 4.88 & 4.85 & 25.3 & 0.151 \\
2 & 5.11 & 4.98 & 23.5 & 0.169 \\
3 & 4.72 & 4.72 & 25.6 & 0.146 \\
4 & 4.36 & 4.24 & 25.0 & 0.056 \\
5 & 4.35 & 4.35 & 20.0 & 0.153 \\
Average & 4.68 & 4.63 & 23.9 & 0.135 \\
St. Dev. & 0.33 & 0.32 & 2.31 & 0.045 \\
\hline
\end{tabular}

Nume sions of properitie tions war simulatio agreemer

It should also be emphasized that the average values of cohesive parameters obtained by this inverse method allow defining the constitutive cohesive laws in pure mode $I$ and in pure mode II. These laws can then be used in progressive damage simulations of bonded joints with this type of adherends and adhesive in order to predict their mechanical behaviour and strength.

\subsubsection{Application to Bonded Joints}

In order to verify the performance of the presented cohesive damage model on joint strength prediction, single lap bonded joints were tested experimentally. The adherends had sixteen layers of unidirectional carbon-epoxy (Table 6.1) giving a nominal thickness of $2.5 \mathrm{~mm}$. The remaining nominal dimensions of the joints were $240 \mathrm{~mm}$ length, $15 \mathrm{~mm}$ width and adhesive thickness of $0.2 \mathrm{~mm}$. Eight different overlap lengths (ranging between 10 and $80 \mathrm{~mm}$ ) were considered. Five specimens of each case were tested and the maximum load was registered and used to define the joint strength. Cohesive failures were observed in all cases. 


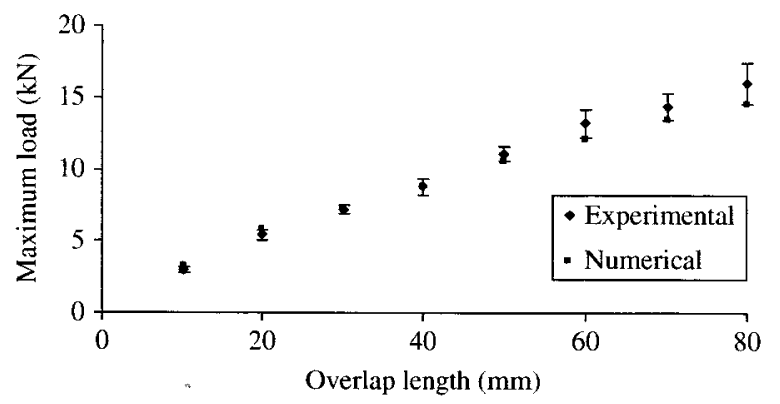

Fig. 6.16 Comparison between numerical and experimental single lap joint strengths as a function of overlap length

Numerical simulations were also performed considering the average real dimensions of each group of five specimens for each tested case. The average cohesive properties measured under pure mode I and under pure mode II in the previous sections were used as inputted data. The maximum loads obtained from these numerical simulations are compared with the experimental ones in Fig. 6.16. Generally, good agreement was obtained for all overlap lengths.

\subsection{Continuum Damage Models}

The cohesive models require the knowledge of the critical zones where damage is prone to occur in order to place the cohesive elements in these critical regions. Continuum damage models can constitute an appealing alternative when damage propagation onset and path are not known a priori. In these models the material properties degradation occurs inside of the solid elements which avoids the use of special interface elements. The application of continuum damage models in the context of bonded joints can be considered interesting when adhesive thickness should be considered. In fact, it is known that adhesive thickness can influence the mechanical properties of the joint [27]. Another example is related to crack propagation occurring near to one interface due to stress concentration [17]. This non-symmetric propagation can induce local mixed-mode loading which is not captured by cohesive damage models where adhesive thickness is neglected. In these cases the adhesive should be simulated by solid elements with the corresponding properties. The progressive damage is simulated by including the damage onset and propagation criteria in the formulation of solid elements. Usually this is performed by means of a user subroutine in standard software where the material properties are degraded according to the chosen criteria.

An approach similar to the one used in the cohesive damage model described in Sect. 6.3 but considering a triangular softening law (see Fig. 6.17), instead of a trapezoidal one, is proposed by several authors $[5,12,32]$. In this case there is a

l on joint . The adIg a nomints were different pecimens to define 


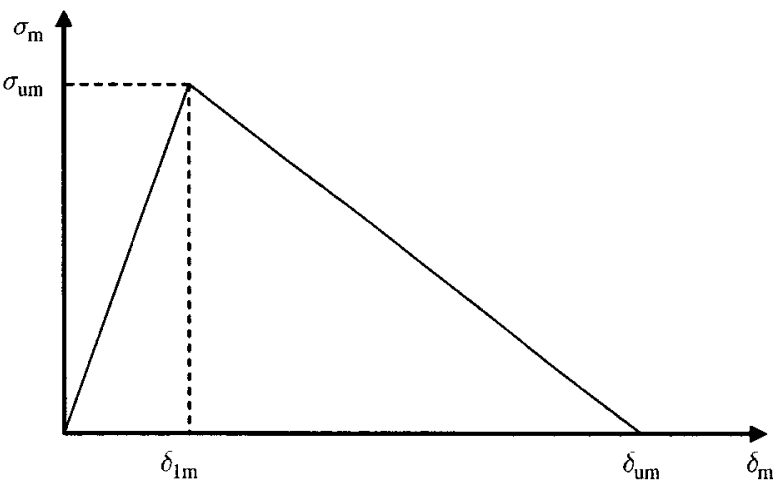

Fig. 6.17 Softening stresses/displacements relationship for the continuum damage model

softening relationship between stresses and strains instead of between stresses and relative displacements considered in the cohesive model. Consequently, a characteristic length $l_{\mathrm{c}}$ must be introduced to transform the relative displacement into an equivalent strain

$$
J_{i \mathrm{c}}=\frac{1}{2} \sigma_{\mathrm{u}, i} \varepsilon_{\mathrm{u}, i} l_{\mathrm{c}, i}
$$

This parameter is equal to the length of influence of a Gauss point in the given direction and physically can be regarded as the dimension at which the material acts homogeneously. It can be obtained from the coordinates of Gauss points available during simulation. The stress-strain relation can be written considering an equation similar to Eq. (6.10)

$$
\boldsymbol{\sigma}=(\mathbf{I}-\mathbf{D}) \mathbf{C} \varepsilon
$$

being $\mathbf{C}$ the stiffness matrix of the undamaged material in the orthotropic directions. Assuming that damage occurs in mixed-mode $(\mathrm{I}+\mathrm{II})$ the model described previously can be adopted.

For the triangular softening model (Fig. 6.17) the damage parameter is given by

$$
d=\frac{\delta_{\mathrm{um}}\left(\delta_{\mathrm{m}}-\delta_{\mathrm{lm}}\right)}{\delta_{\mathrm{m}}\left(\delta_{\mathrm{um}}-\delta_{1 \mathrm{~m}}\right)}
$$

The material properties at a given Gauss point are smoothly degraded according to the assumed criterion, thus simulating the energy releasing at the FPZ. This leads to load redistribution for the neighbouring points, simulating a gradual propagation process and avoiding the stress singularity effects and minimizing the mesh sensitivity effects. As in the cohesive damage model, damage onset and growth are simulated by a quadratic stress criterion and a linear energetic one, respectively, allowing the definition of the critical displacements to be used in Eq. (6.42). More details of the referred model are presented in [15].

Adhes sequent the con dimag: -riteria ical tom 


\subsection{Conclusions}

Adhesive bonded joints are nowadays widely used in structural applications. Consequently, the development of properly design methods is fundamental to increase the confidence of designers in using adhesive bonded joints. Mixed-mode cohesive damage models join the positive arguments of stress based and fracture mechanics criteria overcoming their inherent difficulties. They are presently prominent numerical tools in order to simulate the behaviour of these joints.

In this work a cohesive mixed-mode damage model adequate to the simulation of ductile adhesives is presented. The trapezoidal constitutive softening law simulates the adhesive behaviour including its thickness and plastic behaviour.

An important issue of the model is related to the determination of the cohesive properties. In fact, it is known that adhesive bulk properties are not exactly the same as the ones of a thin adhesive layer. Therefore, they were determined considering fracture tests (DCB and ENF) where the testing conditions are similar to the ones existing in bonded joints. An inverse method was used to define the cohesive parameters. An iterative procedure was followed in order to fit the numerical and experimental $P-\delta$ curves, thus defining the constitutive cohesive laws in the two modes.

A new data reduction scheme based on crack equivalent concept was also proposed to measure the fracture energies in the two fracture characterization tests. The method does not require crack monitoring during its propagation and account for the energy dissipated in the fracture process zone which is not negligible, mainly when ductile adhesives are used. The method was validated by experimental tests and numerical simulations.

Continuum damage models can be a valuable alternative to cohesive damage models especially when adhesive thickness plays an important role on the behaviour of the joint. In this case the adhesive is simulated by solid elements instead of interface ones. The advantage of this approach is related to damage onset and crack propagation path which are better simulated namely when non-symmetric paths can influence the results. The softening laws are applied to the solid elements degrading the material properties according to the predefined criteria. It should also be noted that continuum damage models are more complicated and can lead to numerical problems related to convergence difficulties. Further developments are necessary in this context.

It should be emphasized that the two models can also be used in a bonded joint simulation. In fact, when failure of adherends, for example in composites, is also an issue to be considered, continuum and cohesive damage models can be used to simulate the eventual failure of adherends and adhesive, respectively. The future trends point to the development of a numerical tool incorporating the two kinds of models. The two methods can coexist, although till now there are some unsolved numerical problems. In fact, both models can be implemented via user subroutines in commercial standard software.

according to

? This leads propagation e mesh sen1 growth are respectively, 16.42). More 
Acknowledgements The author thanks the Portuguese Foundation for Science and Technology for supporting part of the work here presented, through the research project $\mathrm{POCI} / \mathrm{EME} / 56567 /$ 2004.

The author also thanks Dr João Paulo Moreira Gonçalves, Dr José Augusto Gonçalves Chousal and Mr Raul Duarte Salgueiral Gomes Campilho (PhD student) for their valorous collaboration. advices and discussion about the matters included in this chapter.

\section{Appendix}

Equation (6.28) can be expressed as,

$$
\alpha a_{\mathrm{e}}^{3}+\beta a_{\mathrm{e}}+\gamma=0
$$

where the coefficients $\alpha, \beta$ and $\gamma$ are, respectively

$$
\alpha=\frac{8}{b h^{3} E_{\mathrm{f}}} ; \quad \beta=\frac{12}{5 b h G_{13}} ; \quad \gamma=-C
$$

Using the Matlab ${ }^{\circledR}$ software and only keeping the real solution we have,

$$
a_{\mathrm{e}}=\frac{1}{6 \alpha} A-\frac{2 \beta}{A}
$$

being

$$
A=\left(\left(1-108 \gamma+12 \sqrt{3\left(\frac{4 \beta^{3}+27 \gamma^{2} \alpha}{\alpha}\right)}\right) \alpha^{2}\right)^{\frac{1}{3}}
$$

\section{References}

1. Andersson T, Stigh U (2004), The stress-elongation relation for an adhesive layer loaded in peel using equilibrium of energetic forces, Int J Sol Struct, 41:413-434

2. Blackman BRK, Hadavinia H, Kinloch AJ, Williams JG (2003), The use of a cohesive zone model to study the fracture of fibre composites and adhesively-bonded joints, Int $J$ Fract, 119:25-46

3. Campilho RDSG, de Moura MFSF, Domingues JJMS (2005), Modelling single and doublelap repairs on composite materials, Comp Sci Technol, 65:1948-1958

4. Charalambides MN, Kinloch AJ, Matthews FL (1997), Strength prediction of bonded joints, AGARD Conference, 83rd Meeting, p. 10.1, AGARD

5. Crisfield M, Mi Y, Davies GAO, Hellweg HB (1997), Finite element methods and the progressive failure modelling of composites structures, in: Computational Plasticity - Fundamentals and Applications (Owen D R J, Oñate E, Hinton E eds.), Barcelona, CIMNE, 239-254

6. Crocombe AD, Adams RD (1982), An elastoplastic investigation of the peel test, J Adhes, $13: 241-267$

7. Cui W, Wisnom MR (1993), A combined stress-based and fracture-mechanics-based model for predicting delamination in composites, Composites, 24:467-474

8. de $\mathbf{x}$ fract

9. de 1 pres: dam

10. de $\mathrm{I}$ appa Mato

11. de 1 acten

12. de I fracs

13. de $\mathrm{N}$ II fic

14. de I tests

15. de I andu tons

16. Dow Grop 415

$1^{-} \cdot \mathrm{Gos}$ $\max$

I. G GI In: Fatr

[4. $\mathrm{H}=\mathrm{I}$

$\pm 0$

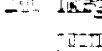

2 IT

45

$=\mathbb{1}$

$\because=$

$-\frac{12}{110}$

$=5-$

in

$=5=$

$8+2$

$I=I$

$\ldots$

$-\quad=$

$\because$.

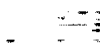

$\because \quad=$

$-$

$=$

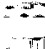


ke and Technology POCI/EME/56567/

Gonçalves Chousal mous collaboration,

have,

sive layer loaded in

of a cohesive zone , joints, Int J Fract

single and double on of bonded joints ods and the progres :ity - Fundamentals NE, 239-254 peel test, J Adhes, hanics-based model
8. de Morais AB, de Moura MFSF (2005), Assessment of initiation criteria used in interlaminar fracture tests of composites, Engng Fract Mech, 72:2615-2627

9. de Moura MFSF, Gonçalves JPM, Marques AT, de Castro PMST (2000), Prediction of compressive strength of carbon-epoxy laminates containing delamination by using a mixed-mode damage model, Comp Struct, 50:151-157

10. de Moura MFSF, Pereira AB, de Morais AB (2004), Influence of intralaminar cracking on the apparent interlaminar model fracture toughness of cross-ply laminates, Fatigue Fract Engng Mater Struct, 27:759-766

11. de Moura MFSF (2006), Numerical simulation of the ENF test for the mode-II fracture characterization of bonded joints, J Adhes Sci Technol, 20:37-52

12. de Moura MFSF, Chousal JAG (2006), Cohesive and continuum damage models applied to fracture characterization of bonded joints, Int J Mech Sci, 48:493-503

13. de Moura MFSF, Silva MAL. de Morais AB, Morais JJL (2006), Equivalent crack based mode II fracture characterization of wood, Engng Fract Mech, 73:978-993

14. de Moura MFSF, de Morais AB (2007), Equivalent crack based analyses of ENF and ELS tests, Eng Fract Mech, 75: 2767-2778

15. de Moura MFSF, Gonçalves JPM, Chousal JAG, Campilho RDSG (2008), Cohesive and continuum mixed-mode damage models applied to the simulation of the mechanical behaviour of bonded joints, Int J Adhes Adhes, doi: 10.1016/j.ijadhadh.2008.04.004

16. Dourado N, Morel S, de Moura MFSF, Valentin G, Morais J (2007), Comparison of fracture properties of two wood species through cohesive crack simulations, composites part A, 39: $415-427$

17. Gonçalves JPM, de Moura MFSF, de Castro PMST (2002), A three-dimensional finite element model for stress analysis of adhesive joints, Int J Adhes Adhes, 22:357-365

18. Gonçalves JPM, de Moura MFSF, Magalhães AG, de Castro PMST (2003), Application of interface finite elements to three-dimensional progressive failure analysis of adhesive joints, Fatigue Fract Engng Mater Struct, 26:479-486

19. Harris JA, Adams RD (1984), Strength prediction of bonded single lap joints by non-linear finite element methods, Int J Adhes Adhes, 4:65-78

20. Ikegami K, Takeshita T, Matsuo K, Sugibayashi T (1990), Strength of adhesively bonded scarf joints between glass fibre-reinforced plastics and metals, Int J Adhes Adhes, 10:199-206

21. Irwin GR (1957), Analysis of stress and strains near the end of a crack traversing a plate, ASME J Appl Mech, 24:361-364

22. John SJ, Kinloch AJ, Matthews FL (1991), Measuring and predicting the durability of bonded carbon fibre/epoxy composite joints, Composites, 22:121-127

23. Kanninen MF, Popelar CH (1985), Advanced fracture mechanics, Oxford University Press, Oxford

24. Kinloch AJ (1987), Adhesion and adhesives: science and technology, Chapman \& Hall, London

25. Krueger R (2002), The virtual crack closure technique: history, approach and applications, NASA/CR-2002-211628, Icase Report No. 2002-10

26. Lammerant L, Verpoest I (1996), Modelling of the interaction between matrix cracks and delaminations during impact of composite plates, Comp Sci Technol, 56:1171-1178

27. Lee DB, Ikeda T, Miyazaki M, Choi NS, (2004), Effect of bond thickness on the fracture toughness of adhesive joints, J Eng Mat Technol, 126:14-18

28. Lee SJ, Lee DG (1992), Development of a failure model for the adhesively bonded tubular single lap joint. J Adhes, 40:1

29. Leffler K, Alfredsson KS, Stigh U (2007), Shear behaviour of adhesive layers, Int J Sol Struct, $44: 530-545$

30. Mi Y, Crisfield MA, Davies GAO, Hellweg H-B (1998), Progressive delamination using interface elements, J Comp Mat, 32:1246-1272

31. Petrossian Z, Wisnom MR (1998), Prediction of delamination initiation and growth from discontinuous plies using interface elements, Composites Part A, 29A:503-515 
32. Pinho ST, Iannuci L, Robinson P (2006), Physically based failure models and criteria for laminated fibre-reinforced composites with emphasis on fibre kinking. Pat II: FE implementation, Composites Part A, 37:766-777

33. Ripling EJ, Mostovoy S, Patrick RL (1963), Application of fracture mechanics to adhesive joints, in: Adhesion, ASTM STP 360, ASTM, Philadelphia, PA

34. Schuecker C, Davidson BD (2000). Evaluation of the accuracy of the four-point bend endnotched flexure test for mode II delamination toughness determination, Compos Sci Technol, 60: $2137-2146$

35. Thouless MD, Waas AM, Schroeder JA, Zavattieri PD (2006), Mixed-mode cohesive-zone models for fracture of an adhesively bonded polymer-matrix composite, Eng Fract Mech, 73:64-78

36. Towse A, Davies RGH, Clarke A, Wisnom MR, Adams RD, Potter KD (1997), The design and analysis of high load intensity adhesively bonded double lap joints. Proceedings of the Fourth International Conference on Deformation and Fracture of composites, Manchester, UK, 479-488

37. Wang Y, Williams JG (1992), Corrections for mode II fracture toughness specimens of composite materials, Comp Sci Technol, 43:251-256

38. Whitney JM, Nuismer RJ (1974), Stress fracture criteria for laminated composites containing stress concentrations, J Comp Mat, 8:253-265

39. Yang QD, Thouless MD, Ward SM (1999), Numerical simulations of adhesively-bonded beams failing with extensive plastic deformation, J Mech Phy Sol, 47:1337-1353

40. Yang QD, Thouless MD (2001), Mixed-mode fracture analyses of plastically deforming adhesive joints, Int J Fract, 110:175-187

41. Yang QD, Thouless MD, Ward SM (2001), Elastic-plastic mode-II fracture of adhesive joints, Int J Sol Struct, 38:3251-3262

42. Zhao X (1991), Stress and failure analysis of adhesively bonded lap joints, $\mathrm{PhD}$ thesis, Department of Mechanical Engineering, University of Bristol, UK 